\title{
Práticas Sociais com Crianças e Adolescentes: O Impacto dos Conselhos Tutelares ${ }^{1}$
}

Social Practices With Children And Adolescents: The Impact Of The Guardian Council
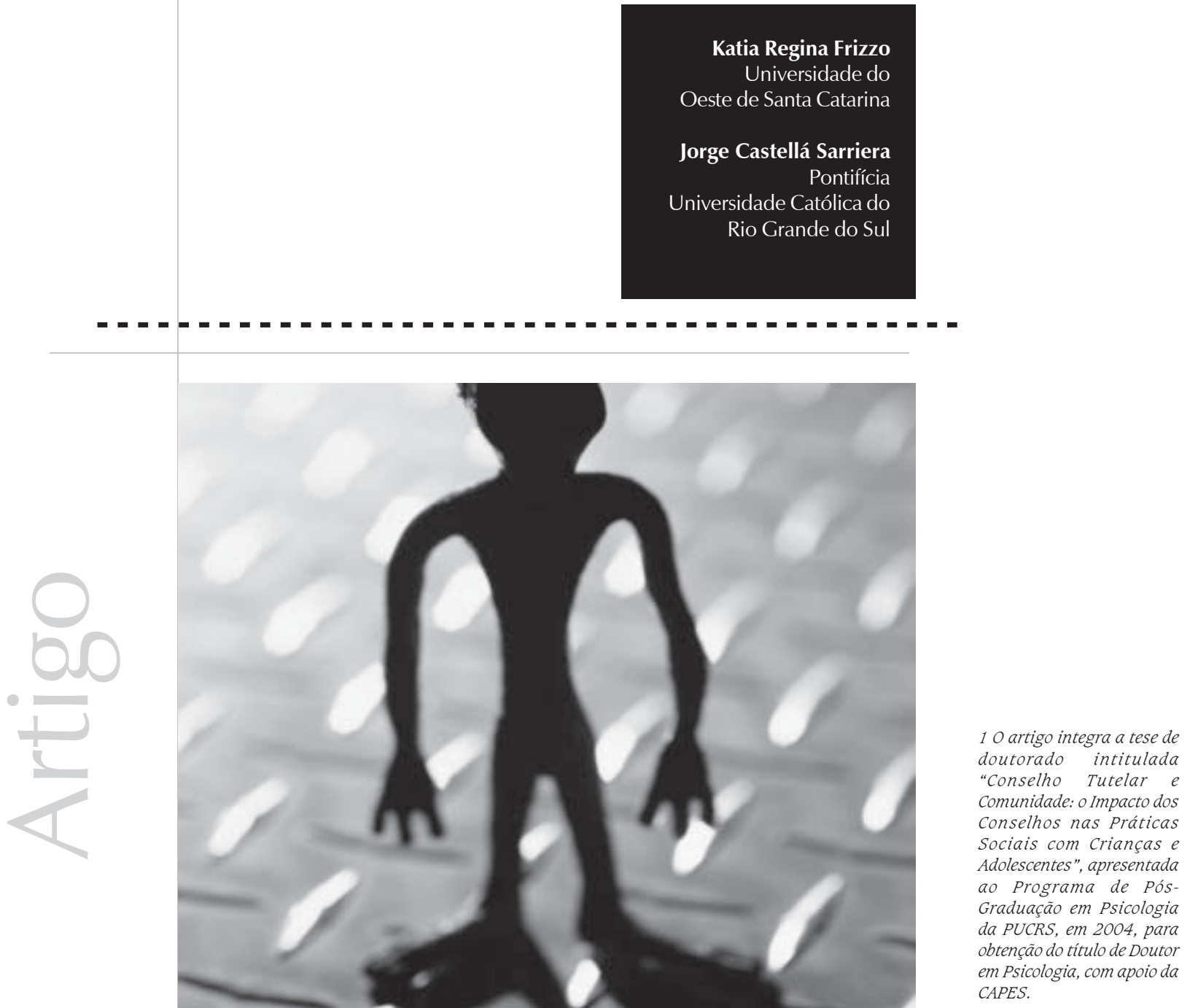


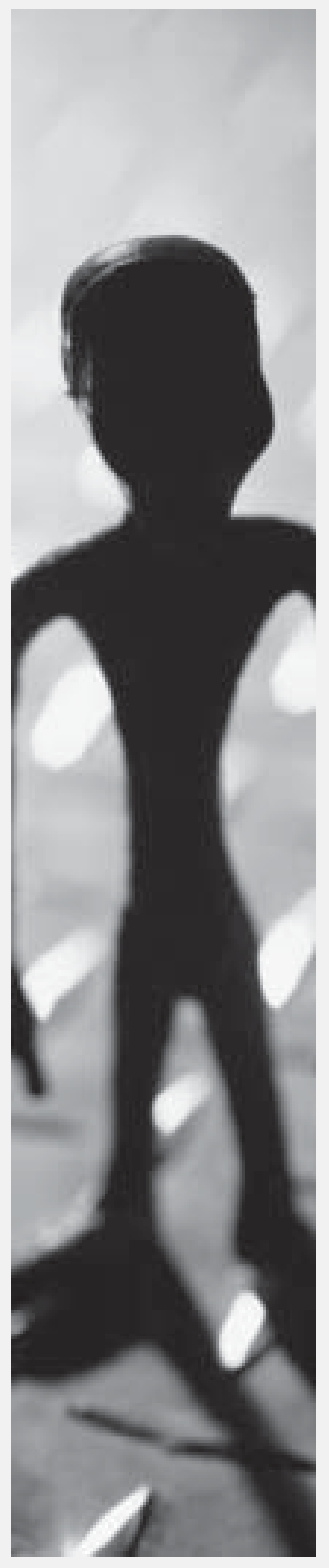

Resumo: As práticas sociais constituem um importante campo de reflexão e pesquisa dentro da Psicologia comunitária latino-americana. As práticas sociais com crianças e adolescentes envolvem principalmente as famílias e as instituições educativas, de saúde e outras. O presente artigo apresenta uma pesquisa realizada com a finalidade de verificar o impacto produzido pela ação do Conselho Tutelar no Município sobre as práticas familiares e institucionais com crianças e adolescentes. Foi realizado um levantamento das estatísticas de atendimento de 2000 a 2003 (quatro anos) do Conselho Tutelar de um Município do meio-oeste do Estado de Santa Catarina. Também foram realizadas algumas entrevistas com profissionais de diferentes setores de atividade que interagem freqüentemente com o Conselho para verificar suas opiniões sobre o mesmo. Os resultados indicaram um impacto maior nas práticas sociais familiares e nas práticas sociais institucionais de saúde. O impacto sobre as práticas institucionais educacionais e de trabalho não é relevante.

Palavras-chave: práticas sociais, conselho tutelar, comunidade.

\begin{abstract}
The social practices constitute an important field of reflection and research within Latin American communitarian Psychology. The social practices with children and adolescents comprehend manly the families and educational institutions, health institutions and others. This article presents a research conducted with the purpose of verifying the impact produced by the action of the guardian council in the community on the family and institutional practices with children and adolescents. A raising of service statistics of the guardian council of a middle-west district of the State of Santa Catarina was done from 2000 to 2003 (four years). Some interviews were also made with professionals from different areas that frequently interact with the council to verify their opinions on it (the council itself). The results indicated a bigger impact on family social practices and on institutional social health practices. The impact on institutional educational and work practices is not relevant.
\end{abstract}

Key words: social practices, guardian council, community.

O campo das práticas sociais tem se revelado um campo fértil para as pesquisas em Psicologia social no País, nos últimos tempos. Após a "virada" da Psicologia social na década de 80, tornou-se importante investigar a produção das condições sociais de existência e isso se dá no terreno das práticas sociais. A ABRAPSO cumpriu importante papel no desenvolvimento da área e constituiu-se um grupo de trabalho sobre a Psicologia social comunitária que desenvolve e divulga as pesquisas da área.

Entendemos por prática social toda prática de interação (= relação) entre sujeitos sociais, em que uns acabam produzindo efeitos em outros, planejada e conscientemente, ou não. Segundo Guareschi (1997, p.13), "é impossível não agir", pois mesmo a omissão ou a ação passiva, quando impede que algo 
aconteça, produz um efeito, e, portanto, é uma prática. As práticas de educação dos filhos, as práticas pedagógicas e as práticas de submissão e poder nas relações de trabalho são exemplos de práticas sociais que produzem efeitos calculados; elas visam a determinados resultados. Outras práticas, como as que se desenvolvem nas relações de gênero, não são necessariamente controladas, mas apontam um sentido de reprodução social de estereótipos e preconceitos. Não há, portanto, como afirma Guareschi (1997), neutralidade na ação.
O desenvolvimento
da Psicologia
comunitária no
Brasil e na América
Latina seguiu o
caminho da
identificação com
os problemas
sociais como
aqueles que
mereciam sua
atenção
privilegiada e com
os setores
populares que
lutavam por uma
sociedade mais
justa como os
segmentos de
desenvolvimento
do seu campo de
atuação
No presente estudo, abordamos as práticas sociais voltadas para as crianças e adolescentes, tanto dentro da família como na escola e em outras instituições sociais. Por exemplo, a prática de bater nos filhos para atingir determinados objetivos de mudança de comportamento (violência física) pode levar a uma intervenção do Conselho Tutelar, caso haja denúncia por parte de vizinhos e/ou outras pessoas. A prática de denunciar também é uma prática social, pois exige a ação do sujeito em favor da defesa de outro/os. É nossa convicção que certas práticas só aprendemos mesmo em comunidade ou pela intervenção externa à família, através de organismos e/ou instituições. Trata-se de uma aprendizagem social produzida pelas interações sociais no desenvolvimento do sujeito. Participar de uma reunião pode não ser uma prática comum, muito menos ainda se exige a nossa participação, entretanto, muitos aprendem a participar dentro de reuniões promovidas pela igreja, pelas escolas, pelas associações de bairro.

O desenvolvimento comunitário apresentase como um campo de práticas associativas e de participação social nos fóruns ou instâncias onde se dão decisões sobre o coletivo social.

\section{A Psicologia social comunitária e seu campo de atuação}

O desenvolvimento da Psicologia comunitária no Brasil e na América Latina seguiu o caminho da identificação com os problemas sociais como aqueles que mereciam sua atenção privilegiada e com os setores populares que lutavam por uma sociedade mais justa como os segmentos de desenvolvimento do seu campo de atuação (Lane, p.1996). Como uma área cuja identidade não estava definida, escorregou nas práticas clínicas como primeira alternativa de ancoragem de sua identidade, mas logo encontrou o caminho da pesquisa e da intervenção participante como forma mais adequada de sua inserção nesse novo campo (Freitas, p.1996).

Os vários enfoques utilizados pela Psicologia social comunitária latino-americana (Montero, 1994) demonstram seu compromisso com a emancipação das classes populares, com a defesa dos direitos humanos e da qualidade de vida da população, e com metodologias de intervenção e de pesquisas que não só privilegiem a participação dos atores envolvidos mas também considerem o saber daqueles a quem se dirige o trabalho como constituinte do conhecimento a ser gerado sobre ele. Nesse sentido, podemos dizer que uma quantidade razoável de trabalhos foram produzidos visando contribuir para a transformação da realidade latino-americana e brasileira, com atuações que vão desde a formação de lideranças na área da saúde e trabalho social, estudos sobre habitação e planejamento urbano e diagnósticos locais, até a construção de centros e programas de intervenção psicológico-comunitária (Wiesenfeld e Sánchez, 1995; Jacób e Torrens, 1998; Sarriera, 2000). A multiplicidade de trabalhos atesta, sem dificuldade, que a Psicologia comunitária 
constitui um campo de saber e de atuação, e que sua identidade está fortemente calcada nos pressupostos da emancipação humana e nas formas de construção conjunta do conhecimento.

Dentre os diversos enfoques para a realização do nosso trabalho, escolhemos o marco ecológico pelas possibilidades de exploração metodológica das relações do Conselho Tutelar, enquanto instituição e, portanto, sistema, com o seu entorno, o meio circundante. É importante considerar que, pelas características do processo de sua construção e legitimação, o Conselho Tutelar possui uma relação muito estreita com a comunidade de que faz parte, pois, diferentemente de outras instituições sociais, ele tem uma base territorial fixa e uma atuação delimitada a ela, seja o Município ou uma região dentro dele.

O enfoque ecológico-contextual foi tematizado por Bronfenbrenner (1996) como uma compreensão sistêmica do desenvolvimento humano. A utilização desse enfoque tem sido crescente, pois possibilita analisar os diferentes níveis e ambientes de que participa uma pessoa para contextualizar seus problemas e/ou as possibilidades de intervenção.

Assim, nossa compreensão focalizará, neste estudo, o Conselho Tutelar em três níveis:

como um microssistema, com um conjunto de atividades, função e atribuições específicas; o enfoque sistêmico ajudar-nosá a abordá-lo desde uma perspectiva do CT enquanto instituição (sistema);

- as relações do sistema CT com outros microssistemas, como a família, a escola, os serviços públicos de saúde, habitação, segurança e outros; trata-se da relação do sistema com seu ambiente; a comunidade, entendida como o campo onde se dá a atuação do CT, e onde o sistema produz impactos duradouros na vida social.

Ao abordar o Conselho Tutelar da perspectiva de uma instituição (Nasciutti, 1996, p.114), estamos considerando que as instituições sejam "espaços de mediação entre a vida individual e a vida coletiva". Ao analisá-lo como um sistema (Campanini e Luppi, 1996), estamos enfatizando o ambiente dinâmico e o sistema de trocas em que se insere. O desenvolvimento comunitário seria o efeito sistêmico da atuação de um subsistema responsável pela defesa da ordem democrática e de seus imperativos de participação (Aragão, p. 2001).

\section{A construção dos indicadores de atendimento}

A utilização de indicadores na pesquisa social serve para tornar evidentes aqueles processos de mudança provocados por algum tipo de intervenção social. Segundo Armani (2000, p.58), "um indicador é um instrumento de medição usado para indicar mudanças na realidade social que nos interessa". Não existem, portanto, indicadores "a priori", pois devemos inicialmente definir em qual realidade esperamos verificar tais mudanças e quais mudanças pretendemos medir.

Para a compreensão do que estamos denominando por "práticas sociais", tomamos como referência a reflexão de Guareschi (1997, p. 13) que nos diz:

"No entender tradicional do que é agir, ou exercer uma prática, somente há "prática" quando interfiro positivamente. $\mathrm{O}$ agir "passivamente" não seria prática, apesar de, em alguns casos, acontecer muita coisa exatamente porque "permiti", ou "me omiti". Já na visão da sociedade como um rio, como
"No entender tradicional do que é agir, ou exercer uma prática, somente há "prática" quando interfiro positivamente. 0 agir "passivamente" não seria prática, apesar de, em alguns casos, acontecer muita coisa exatamente porque "permiti", ou "me omiti". Já na visão da sociedade como um rio, como algo construído sobre "relações", que implicam sempre algo dinâmico, mudança, contradição, é impossível "não agir". Isto é, sempre há uma prática, de nossa parte..."

Guareschi 
algo construído sobre "relações", que implicam sempre algo dinâmico, mudança, contradição, é impossível "não agir". Isto é, sempre há uma prática, de nossa parte..."

Assim, entendemos que o Conselho Tutelar institui uma nova prática entre outras práticas que podem ser consideradas no trato das questões da infância. As práticas educativas, por exemplo, constituem um tipo de prática social na infância. As diversas práticas profissionais, então, constituem outro tipo de práticas sociais.

Segundo nossa hipótese de trabalho, pretendemos demonstrar que os Conselhos Tutelares produzem mudanças em algumas dimensões da realidade social, que denominamos conceitualmente de "práticas sociais", já que ele interage com diversos setores da sociedade e produz algum impacto nas práticas sociais desses setores.

\section{Método}

Para observar e medir o impacto da ação dos Conselhos Tutelares sobre as práticas sociais voltadas para crianças e adolescentes, realizamos uma análise das estatísticas de atendimento de um Conselho Tutelar durante um período de quatro anos.

Como se tratam de conceitos subjetivos que indicam qualidades, buscamos tornar essas dimensões visíveis e operacionalizáveis em termos de indicadores, usando algumas estatísticas produzidas pelo Conselho Tutelar "A" através do sistema SIPIA (Sistema de Informações para a Infância e a Adolescência). Pelo SIPIA, os direitos violados são categorizados de acordo com o que dispõe o Estatuto da Criança e do Adolescente. Assim, por exemplo, sob a rubrica 1.0.00.0, temos um bloco de seis violações do direito à VIDA E SAÚDE, de que trata o Capítulo I dos Direitos Fundamentais elencados no Estatuto da Criança e do Adolescente (artigos $7^{\circ}$ a $14^{\circ}$ ). Na rubrica 2.0.00.0, temos mais um bloco de sete violações do direito à LIBERDADE, RESPEITO, DIGNIDADE, e assim por diante. Com base nesse sistema de registro, construímos uma forma de produção dos indicadores sobre as práticas sociais. O sistema foi desenvolvido nacionalmente para fins exclusivos de utilização pelos Conselhos Tutelares, com o objetivo de padronizar os dados de atendimento.

Para fins de análise, utilizaremos como referência duas experiências ou dimensões da realidade social que são marcadas pela presença de padrões estruturados de comportamentos estreitamente relacionados ao exercício de um papel social, que configuram práticas sociais e que são as práticas sociais familiares e as práticas sociais institucionais.

As práticas sociais familiares constituem aqueles comportamentos característicos dos papéis familiares. Assim, pai e mãe têm por dever educar os filhos e utilizam seus próprios métodos educativos para educá-los. Também têm o dever de prover o sustento da casa, ainda que contem com a ajuda de outros adultos da família, adolescentes e/ou membros da família extensa para exercer adequadamente o seu papel (Osório, 1996).

Podemos visualizar a forma de produção dos indicadores sobre as práticas sociais nas famílias pelo seguinte quadro demonstrativo, onde a terceira coluna representa o conjunto das estatísticas extraídas diretamente do SIPIA de 1999 a 2003 : 


\begin{tabular}{|c|c|c|}
\hline Conceito & Variáveis & Indicadores \\
\hline \multirow{10}{*}{$\begin{array}{l}\text { Práticas } \\
\text { sociais nas } \\
\text { famílias }\end{array}$} & \multirow{5}{*}{$\begin{array}{l}\text { 1) Melhora nas práticas de } \\
\text { cuidado e educação dos filhos; }\end{array}$} & *índices de aprisionamento ; \\
\hline & & *índices de violência física; \\
\hline & & *índices de violência psicológica; \\
\hline & & *índices de ausência de convívio familiar; \\
\hline & & *índices de ausência de infraestrutura. \\
\hline & \multirow{4}{*}{$\begin{array}{l}\text { 2) Criação de ambientes } \\
\text { familiares mais harmônicos; }\end{array}$} & *índices de inadequação do convívio familiar; \\
\hline & & *índices de inadequação do convívio familiar; \\
\hline & & *índices de atos atentatórios à cidadania; \\
\hline & & $\begin{array}{l}\text { *índices em que o agente violador é a família } \\
\text { (conjunto) ou outros familiares; }\end{array}$ \\
\hline & $\begin{array}{l}\text { 3) Melhoria das relações } \\
\text { parentais com as crianças } \\
\text { e adolescentes. }\end{array}$ & $\begin{array}{l}\text { *índices em que os pais aparecem como } \\
\text { agente violador; }\end{array}$ \\
\hline
\end{tabular}

Figura. 1. Quadro conceitual das práticas sociais familiares

As práticas sociais institucionais estão relacionadas, por sua vez, com o exercício dos papéis profissionais e com as dinâmicas próprias das instituições do campo social, onde são executados serviços públicos destinados ao atendimento das necessidades básicas dos cidadãos (políticas públicas de educação, saúde, habitação, etc.) e/ou programas destinados a um segmento social necessitado de proteção especial (programas de proteção especial, segundo o ECA).

\begin{tabular}{|c|c|c|}
\hline Conceito & Variáveis & Indicadores \\
\hline \multirow{19}{*}{$\begin{array}{l}\text { Práticas } \\
\text { sociais } \\
\text { institucionais }\end{array}$} & \multirow{7}{*}{$\begin{array}{l}\text { 1)práticas } \\
\text { institucionais na } \\
\text { área de saúde; }\end{array}$} & *índices de não atendimento médico ; \\
\hline & & *índices de atendimento médico deficiente; \\
\hline & & *índices de prejuízos por ação ou omissão de agente externo; \\
\hline & & *índices de práticas hospitalares e ambulatoriais irregulares; \\
\hline & & *índices de irregularidades na garantia da alimentação; \\
\hline & & *índices de atos atentatórios à vida; \\
\hline & & *índices em que o agente violador é o posto de saúde; \\
\hline & \multirow{6}{*}{$\begin{array}{l}\text { 2) práticas } \\
\text { institucionais } \\
\text { na área } \\
\text { educacional; }\end{array}$} & *índices de impedimento de acesso à educação; \\
\hline & & *índices de impedimento de permanência no sist. escolar; \\
\hline & & *índices de ausência de condições educacionais adequadas; \\
\hline & & *índices de cultura/esporte/lazer; \\
\hline & & *índices de ausência ou impedimento do uso de equipamentos; \\
\hline & & *índices em que o agente violador é escola/creche; \\
\hline & \multirow{6}{*}{$\begin{array}{l}\text { 3) práticas } \\
\text { institucionais no } \\
\text { mercado de } \\
\text { trabalho; }\end{array}$} & *índices de exploração do trabalho infantil; \\
\hline & & *índices de condições adversas de trabalho; \\
\hline & & *índices de inobservância da legislação trabalhista; \\
\hline & & *índices de ausência de condições para a formação e \\
\hline & & desenvolvimento; \\
\hline & & $\begin{array}{l}\text { *índices em que o agente violador é } \\
\text { estabelecimento comercial. }\end{array}$ \\
\hline
\end{tabular}

Figura. 2. Quadro conceitual das práticas sociais institucionais 
Através dessas dimensões das práticas sociais, pretendemos demonstrar que a intervenção do Conselho Tutelar na realidade social produz algum impacto no sentido de reduzir ou aumentar esses índices. Em alguns casos, o impacto é tão insignificante que podemos dizer mesmo que é nulo.

Além da realização desse trabalho com indicadores, foram realizadas entrevistas com profissionais do campo social que interagem freqüentemente com o Conselho Tutelar, de modo a buscar a percepção externa sobre o trabalho do Conselho e algumas indicações das possíveis mudanças na vida social a partir da existência e do contato com o Conselho Tutelar.

Para auferir o impacto produzido pelo Conselho Tutelar, foi preciso também determinar limites dentro dos quais passamos a considerar o impacto nos indicadores, que foram estabelecidos nos seguintes níveis:

(0) inexistente - entre 0\% e 20\% de variação no número de atendimentos;

(1) irrelevante - entre $20 \%$ e $40 \%$ de variação;

(2) significativo - entre $40 \%$ e $70 \%$ de variação;

(3) importante - acima de 70\% de variação.

Os indicadores de impacto também foram classificados de acordo com o sentido do impacto em: impacto negativo, quando a variação foi no sentido do aumento no número de atendimentos, e impacto positivo, quando a variação indicou a diminuição do número de registros (Pereira, 2001).

\section{Resultados e discussão}

Através da análise dos indicadores, pôde-se constatar que o Conselho Tutelar produz mudanças nas práticas sociais em níveis diferenciados nas famílias e nas instituições.

\section{Práticas sociais nas famílias}

A família constitui o primeiro grupo social de uma criança. Nela formam-se os hábitos e comportamentos que apresentam mais resistência à mudança externa, pois baseiamse em relações afetivas intensas e marcadas pelas relações de dependência entre os filhos e seus pais ou adultos cuidadores (Brant de Carvalho et al., 1995).

As práticas de educação dos filhos são transmitidas de geração em geração através de tradições familiares, que só são questionadas quando outros grupos ou instituições sociais confrontam seus saberes e práticas com as práticas familiares. É o caso da escola, por exemplo, que pode constituir uma fonte de aprendizagem para os pais e para as crianças no que se relaciona às práticas adequadas de cuidado com os filhos. É o caso, também, da intervenção do Conselho Tutelar, que pode qualificar como inadequadas certas práticas pedagógicas familiares tradicionais, obrigando os pais, principalmente, a mudar certos hábitos domésticos de cuidado e educação dos filhos. É o caso da violência física, da negligência, da violência psicológica, por exemplo.

$\mathrm{Na}$ análise das práticas sociais familiares, podemos dizer que, do total de oito indicadores considerados, cinco apresentaram impacto positivo, e apenas três, impacto negativo. O impacto médio é de 1,75, ou seja, um impacto irrelevante, mas próximo de tornar-se um impacto significativo. As variáveis que apresentaram um impacto positivo, ou seja, apresentaram sensível diminuição nos últimos quatro anos, foram as práticas de cuidado e educação dos filhos. Os índices que mais contribuíram para a mudança foram: - violência física (28\%);

- violência psicológica (69\%);

ausência de convívio familiar (69\%);

- atos atentatórios à cidadania (54\%) e

agente violador: pais e família/outros (28\%). 


\begin{tabular}{|c|c|c|c|c|c|c|c|c|}
\hline $\begin{array}{l}\text { Tipo de } \\
\text { prática } \\
\text { social }\end{array}$ & $\begin{array}{l}\text { Perfil das } \\
\text { violações }\end{array}$ & 2000 & 2001 & 2002 & 2003 & $\begin{array}{l}\text { Var. } \% \\
00-03\end{array}$ & $\begin{array}{l}\text { Nível } \\
\text { do impacto }\end{array}$ & $\begin{array}{l}\text { Qual. } \\
\text { Do impacto }\end{array}$ \\
\hline \multirow{5}{*}{$\begin{array}{l}\text { práticas de } \\
\text { cuidado e } \\
\text { educação } \\
\text { dos filhos }\end{array}$} & aprisionamento & 05 & 04 & 05 & 07 & $40 \%$ & 1 & Neg. \\
\hline & violência física & 39 & 39 & 33 & 28 & $28 \%$ & 1 & Pos. \\
\hline & $\begin{array}{l}\text { violência } \\
\text { psicológica }\end{array}$ & 23 & 11 & 28 & 07 & $69 \%$ & 2 & Pos \\
\hline & $\begin{array}{l}\text { ausência de } \\
\text { convívio } \\
\text { familiar }\end{array}$ & 82 & 54 & 52 & 25 & $69 \%$ & 2 & Pos \\
\hline & $\begin{array}{l}\text { ausência de } \\
\text { infraestrutura }\end{array}$ & - & 04 & 17 & 02 & $200 \%$ & 3 & Neg. \\
\hline \multirow[t]{2}{*}{$\begin{array}{l}\text { ambiente } \\
\text { familiar }\end{array}$} & $\begin{array}{l}\text { inadequação do } \\
\text { conv. familiar }\end{array}$ & 179 & 199 & 143 & 276 & $54 \%$ & 2 & Neg. \\
\hline & $\begin{array}{l}\text { atos atentatórios } \\
\text { à cidadania }\end{array}$ & 68 & 71 & 60 & 30 & $56 \%$ & 2 & Pos \\
\hline $\begin{array}{l}\text { relações } \\
\text { parentais }\end{array}$ & $\begin{array}{l}\text { agente violador } \\
\text { : pais }\end{array}$ & 327 & 318 & 327 & 253 & $24 \%$ & 1 & Pos. \\
\hline
\end{tabular}

Figura. 3. Práticas sociais familiares

Como mostra a figura 3, houve uma diminuição sensível de registros de atendimento nesses itens, possivelmente por constituírem aspectos bastante visíveis das relações familiares, como é o caso da violência física e da violência psicológica, bem como da ausência de convívio familiar, que nada mais é do que o abandono dos filhos à própria sorte. A violência psicológica geralmente está associada à violência física, pois apresenta índices muito semelhantes. Outro fator que pode ter contribuído para a redução desses índices é a inclusão das famílias em programas de apoio socio-familiar, que aportem recursos materiais e/ou educativos para a mudança nas práticas educativas domésticas. Entretanto, podemos relacionar esse fator como resultante indiretamente da intervenção do Conselho, haja vista que uma das suas funções é justamente monitorar a política de atendimento, sugerindo a criação de programas para atendimento dos direitos fundamentais, expressos na lei.

\section{Práticas sociais institucionais}

As práticas sociais examinadas neste trabalho não abrangem todas as instituições que desenvolvem programas e/ou atividades com crianças e adolescentes. Elas restringem-se apenas a alguns setores de atividade, como a saúde e educação, pois são itens que permitem a comparabilidade dos dados, enquanto as entidades e programas são incomparáveis devido à inconstância de sua existência e atendimento, configurando a saúde e a educação políticas públicas que menos sofrem descontinuidade nas suas ações.

As práticas sociais institucionais apresentaram menos indicadores com impacto positivo. Do total de quinze indicadores, apenas $1 / 3$ (cinco) apresentaram impacto positivo, enquanto todos os demais apresentaram impacto negativo. O impacto médio é de 2,53 , o que consideramos um impacto significativo, embora no sentido predominantemente negativo.
A violência psicológica geralmente está associada à violência física pois apresenta indices muito semelhantes. 


\begin{tabular}{|c|c|c|c|c|c|c|c|c|}
\hline $\begin{array}{l}\text { Tipo de } \\
\text { prática } \\
\text { social }\end{array}$ & $\begin{array}{l}\text { perfil das } \\
\text { violações }\end{array}$ & 2000 & 2001 & 2002 & 2003 & $\begin{array}{l}\text { Var. } \% \\
00-03\end{array}$ & $\begin{array}{l}\text { Nível do } \\
\text { impacto }\end{array}$ & $\begin{array}{l}\text { Qual. do } \\
\text { impacto }\end{array}$ \\
\hline \multirow{7}{*}{$\begin{array}{l}\text { práticas } \\
\text { insti- } \\
\text { tucionais } \\
\text { na área } \\
\text { da saúde }\end{array}$} & não atendimento médico & 12 & 23 & 03 & - & $100 \%$ & 3 & Positivo \\
\hline & $\begin{array}{l}\text { atendimento médico } \\
\text { deficiente }\end{array}$ & 11 & 04 & 05 & 01 & $91 \%$ & 3 & Positivo \\
\hline & $\begin{array}{l}\text { prejuízos por ação/omissão ag. } \\
\text { externo }\end{array}$ & 09 & 03 & 05 & 04 & $55 \%$ & 2 & Positivo \\
\hline & $\begin{array}{l}\text { práticas hospitalares e } \\
\text { ambulatoriais irregulares; }\end{array}$ & 03 & - & 01 & - & $100 \%$ & 3 & Positivo \\
\hline & $\begin{array}{l}\text { irregularidade na garantia } \\
\text { da alimentação; }\end{array}$ & - & 01 & - & 08 & $100 \%$ & 3 & Negativo \\
\hline & $\begin{array}{l}\text { atos atentatórios à vida; } \\
\text { agente violador: posto }\end{array}$ & 02 & - & - & 09 & $350 \%$ & 3 & Negativo \\
\hline & de saúde; & 06 & 08 & 05 & 09 & $50 \%$ & 2 & Negativo \\
\hline \multirow{4}{*}{$\begin{array}{l}\text { práticas insti- } \\
\text { tucionais na } \\
\text { área da } \\
\text { educação }\end{array}$} & impedimento de acesso; & 25 & 20 & 03 & 34 & $36 \%$ & 1 & Negativo \\
\hline & $\begin{array}{l}\text { impedimento de permanência; } \\
\text { ausência de condições }\end{array}$ & 06 & 09 & 01 & 08 & $33 \%$ & 1 & Negativo \\
\hline & educacionais adequadas; & 39 & 47 & 03 & 15 & $61 \%$ & 2 & Positivo \\
\hline & agente violador: esc./creche; & 01 & 04 & 01 & 10 & $900 \%$ & 3 & Negativo \\
\hline \multirow{4}{*}{$\begin{array}{l}\text { práticas insti- } \\
\text { tucionais no } \\
\text { mercado de } \\
\text { trabalho }\end{array}$} & exploração trabalho infantil; & - & 05 & 04 & 2 & $200 \%$ & 3 & Negativo \\
\hline & inobservância da legislação; & 01 & 01 & 02 & 02 & $100 \%$ & 3 & Negativo \\
\hline & ausência de condições; & - & 05 & 01 & 02 & $200 \%$ & 3 & Negativo \\
\hline & agente violador: est. comercial. & - & 09 & 06 & 03 & $300 \%$ & 3 & Negativo \\
\hline
\end{tabular}

Figura 4. Práticas sociais institucionais

As práticas sociais institucionais que apresentaram uma diminuição sensível no registro de atendimentos localizam-se principalmente entre os indicadores de saúde, demonstrados na figura 4 . O impacto sobre as práticas dessa área é significativo, com média 2,71. Sofreram alguma diminuição dos índices de atendimento, com impacto positivo na área da saúde, as seguintes situações registradas no SIPIA:

não atendimento médico (100\%);

atendimento médico deficiente (91\%);

- prejuízos por ação/omissão de agente externo (55\%) e

opráticas hospitalares e ambulatoriais irregulares (100\%).
Entre as práticas sociais registradas na educação, apenas o item "ausência de condições educacionais adequadas" apresentou uma diminuição nos registros (61\%), enquanto os outros três indicadores apresentaram resultados negativos. O impacto é irrelevante, com média 1,75. Ressalte-se que dois importantes direitos são registrados nesse bloco, e apresentaram aumento dos registros nos quatro anos examinados, configurando flagrante desrespeito aos direitos fundamentais estabelecidos constitucionalmente: acesso e permanência na escola. O quadro preocupa, principalmente porque a educação concentra as expectativas sociais de melhora do quadro de exclusão social com que sofrem muitas famílias em razão de pobreza e de dificuldades 
a ela associadas, como a falta de qualificação, o trabalho infantil e o envolvimento em problemas com a Lei por falta de perspectivas positivas em relação à inserção no mundo do trabalho.

No mercado de trabalho, os resultados são paradoxais, pois o impacto na área é importante (média 3,0) e negativo, mas, considerando-se o baixo número de registros desse grupo de indicadores nos quatro anos examinados, não se pode afirmar que o quadro preocupe.

Um exame atento dos indicadores e de seus respectivos números, entretanto, não nos permite afirmar com clareza que a variação se deve exclusivamente à intervenção do Conselho Tutelar. Na verdade, são muitos os fatores concorrentes para produzir tais resultados: por um lado, temos, na série de quatro anos examinados, uma gestão inteira (2000-2002) e uma parte de outra gestão, quando todos os conselheiros foram renovados. Essa realidade, porém, é representativa dos problemas dos Conselhos. Outro aspecto que limita o alcance explicativo da pesquisa é a interferência dos fatores de variação individual dos conselheiros. Entretanto, optamos por não introduzir tais variáveis neste estudo, uma vez que distorceriam o seu foco principal, que pretende ser sobre o Conselho Tutelar como instituição e sistema, e não sobre os conselheiros, considerados individualmente.

\section{A visão dos profissionais}

A fala dos profissionais é significativa, pois apresenta claras distinções a partir do lugar de onde cada um se posiciona na rede social de apoio à infância.

Assim, as crianças são vistas pelos educadores apenas como "alunos", o que parece qualificar a relação que se estabelece na escola como uma relação única e exclusivamente pedagógica. A professora entrevistada, com dezoito anos de experiência profissional e cujo contato com o Conselho Tutelar é "quase semanal", disse que não desenvolve atividades diretamente com crianças e adolescentes, "só pedagógicas", o que parece restringir sua responsabilidade frente aos graves problemas que ela própria aponta nas crianças e adolescentes de hoje: "falta de concentração, hiperatividade e falta de limites".

É flagrante o descompasso: em lugar de se colocar como recurso educativo complementar à família nesses aspectos, a escola se descompromete, recusando sua responsabilidade na mudança da realidade de vida das crianças e adolescentes. A avaliação sobre o trabalho do Conselho Tutelar no Município não surpreende: é negativa, "deixa muito a desejar", segundo a professora, que parece não confiar muito no trabalho do Conselho.

Por outro lado, os profissionais da saúde entendem de forma mais positiva o trabalho do Conselho, mas consideram precária a sua preparação para o trabalho de responsabilidade que executam. A assistente social, com experiência no trabalho de assistência a famílias economicamente carentes em dois Municípios, considera que o Conselho seja muito importante no Município, mas os conselheiros "são pouco preparados", o que deixa a atuação de alguns aquém do desejado. Já a enfermeira, com três anos de experiência, sente a falta do retorno do Conselho diante dos casos acompanhados. Já foi procurada pelo Conselho e também teve de procurá-lo em diversas situações, e comenta que "eles deveriam dar o retorno sobre a situação, a gente fica querendo saber". Ela insiste que não é para controlar o trabalho do Conselho, mas que "todo mundo quer saber como ficou a situação daquela criança, ou daquela família", evidenciando a necessidade dos profissionais de saber dos encaminhamentos dados pelo Conselho aos atendimentos. 
Essa característica de pouco comprometimento com a prestação de contas do seu trabalho também foi evidenciada por Sierra (2003) nos Conselhos do Rio de Janeiro. Por outro lado, podemos perceber na fala da enfermeira que, ao atuar ao lado do Conselho junto a uma família, a uma criança, enfim, ao interagir com o Conselho, desenvolve-se uma expectativa que é própria dos profissionais do campo técnico-científico, de reciprocidade na relação, de compartilhamento das responsabilidades frente às soluções e de expectativas de sucesso da ação que alimenta cotidianamente a autoestima dos profissionais e a confiança no seu processo de formação.

O delegado tem outra experiência com o Conselho. Com vinte e sete anos de experiência profissional, ele diz que começou a interagir com os Conselhos desde a aprovação do Estatuto, desde que eles foram instalados. Sente que os conselheiros são "pouco preparados", apesar da "boa vontade". Seu contato com o Conselho Tutelar é freqüente, mas não sistemático. A polícia está sempre à disposição do Conselho para fazer qualquer abordagem domiciliar que envolva algum risco. Segundo o delegado, "a gente sempre ajuda, assim, quando tem um caso complicado, um pai bêbado, ou que bateu no filho e tá agressivo... então a gente vai junto, acompanha o Conselho". Outra fonte de contatos é através dos atos infracionais cometidos por adolescentes, quando o Conselho é chamado à delegacia para fazer encaminhamentos.

Os técnicos do sistema judiciário são os que têm mais contato sistemático com o Conselho tutelar. A assistente social diz: "a gente está sempre em contato, tem que estar, pois fazemos muito acompanhamento de casos juntos", referindo-se a casos de violência, abandono e negligência, em que os pais correm o risco de perder o pátrio poder. O Conselho Tutelar acompanha as famílias através da aplicação de medidas de apoio sociofamiliar. As comissárias de menores também tem bastante contato com o Conselho. Compartilham com a assistente social a percepção de que falta qualificação para os conselheiros atuarem, que eles tentam fazer um bom trabalho, mas falta formação para isso, e que o trabalho do Conselho é um trabalho "que exige muito", ou seja, que precisa ser valorizado.

Percebe-se, dessa forma, que os profissionais já assimilaram o papel do Conselho Tutelar na comunidade e entendem o seu valor. Suas críticas se dirigem, via de regra, aos conselheiros, cuja qualificação é posta em dúvida frente à magnitude da importância que adquire o Conselho na sua tarefa de zelar pelos direitos da criança e do adolescente. O problema da qualificação parece o nó da questão, portanto. A identidade do Conselho está estreitamente relacionada à aquisição de habilidades, por um lado, e ao processo de legitimação, por outro.

Outro fator a ser considerado é que a maioria dos profissionais não recebe formação específica sobre direitos da criança e adolescente nem informações adequadas sobre o Conselho Tutelar. Somente o delegado e os comissários da infância e juventude disseram ter recebido alguma formação sobre esses aspectos. Os demais nunca tiveram em sua formação alguma disciplina ou conteúdos que os preparassem para o trabalho com o Conselho. Na prática, entretanto, hoje eles incorporam alguns procedimentos que antes não existiam sempre que têm de interagir com o Conselho Tutelar.

Entendemos que o impacto produzido pelo Conselho nas práticas sociais demonstra-se através dos dados apresentados. A existência de um órgão que participa da esfera pública na defesa dos direitos da criança e do adolescente implicou e está implicando mudanças nas práticas dos profissionais, na prática de muitos setores de atividades e das famílias também. Com certeza, a consciência sobre os direitos da infância está mais difundida que alguns anos atrás, antes da existência dos Conselhos. Entretanto, cabe a todo percurso coerente de investigação reconhecer os limites do conhecimento como algo inerente ao processo de construção científica. Muitas perguntas ficam ainda sem resposta diante desta pesquisa, e suscitam novas investigações que pretendemos empreender. 
ARAGÃO, Elizabeth Maria Andrade. Recorte de uma Realidade: em Busca da Construção de Cidadania. In Novo, Helerina A.; Souza, Lídio de ; Andrade, Angela Nobre de. Ética, Cidadania e Participação. Debates no Campo da Psicologia. Vitória: EDUFES: CCHN Publicações, 2001, pp. 43-60.

ARMANI, Domingos. Como Elaborar Projetos? Guia Prático para Elaboração e Gestão de Projetos Sociais. Porto Alegre: Tomo Editorial, 2000.

BRANT DE CARVALHO, Maria do Carmo et al. A Família Contemporânea em Debate. São Paulo: EDUC/Cortez, 1995.

CAMPANINI, Annamaria y LUPPI, Francesco. Servicio Social y Modelo Sistémico. Buenos Aires: Paidós,1996.

\section{ESTATUTO DA CRIANÇA E DO ADOLESCENTE. Lei No. 8.069.}

FREITAS, Maria de Fátima Quintal de. Psicologia na Comunidade, Psicologia da Comunidade e Psicologia (Social) Comunitária: Práticas da Psicologia em Comunidade nas Décadas de 60 a 90, no Brasil. In Campos, Regina Helena de Freitas. Psicologia Social Comunitária: da Solidariedade à Autonomia. Petrópolis, RJ: Vozes, 1996, pp. 5480.

GUARESCHI, Pedrinho. Qual a "Prática" da Psicologia Social da ABRAPSO? In Zanella, Andréa et al. Psicologia e Práticas Sociais. Porto Alegre: ABRAPSOSUL, 1997, pp.11-16.

JACOB, Mariane Krause y TORRÉNS, Andrea Jaramillo. Intervenciones Psicológico-Comunitarias en Santiago de Chile. Santiago: Pontificia Universidad Católica de Chile, 1998.
Katia Regina Frizzo

Doutoranda PICDT/CAPES em Psicologia da PUCRS.

UNOESC - Universidade do Oeste de Santa Catarina

Rua Getúlio Vargas, 2125 Bairro Flor da Serra E-mail: kátiantizzo@unoesc.edubr

Jorge Castellá Sarriera Professor orientador.

PUCRS - Pontifícia Universidade Católica do Rio Grande do Sul

Av. Ipiranga, 6681Prédio $11-9^{\circ}$ andar, sala 929.

90619-900 - Porto Alegre - RS Fone: 51-3320-3633

E-mail: sarriera@terra.com.br

Recebido 19/04/05 Aprovado 11/03/06
LANE, Sílvia Tatiana Maurer. Histórico e Fundamentos da Psicologia Comunitária no Brasil. In Campos, Regina Helena de Freitas. Psicologia Social Comunitária: da Solidariedade à Autonomia. Petrópolis, RJ: Vozes, 1996, pp.17-34.

MONTERO, Maritza. Psicología Social Comunitaria. México: Universidad de Guadalajara, 1994.

NASCIUTTI, Jacyara C. Rochael. A Instituição como Via de Acesso à Comunidade. In Campos, Regina Helena de Freitas. Psicologia Social Comunitária: da Solidariedade à Autonomia. Petrópolis, RJ: Vozes, 1996, pp. 100-126.

OSÓRIO, Luiz Carlos. Família Hoje. Porto Alegre: Artes Médicas, 1996.

PEREIRA, Júlio César Rodrigues. Análise de Dados Qualitativos: Estratégias Metodológicas para as Ciências da Saúde, Humanas e Sociais. $3^{\mathrm{a}}$ ed. São Paulo: EDUSP/FAPESP, 2001.

SARRIERA, Jorge Castellá. O Modelo Ecológico-Contextual em Psicologia Comunitária. In Sarriera, Jorge Castellá. Psicologia Comunitária: Estudos Atuais. Porto Alegre: Sulina, 2000, pp.373395.

SIERRA, Vania Morales. Conselho Tutelar: uma Identidade em Questão. http://www.abmp.org.br. Portal_ABMP_Publicação 530, 2003.

WIESENFELD, Esther y SÁNCHEZ, Euclides. Psicología Social Comunitaria: Contribuciones Latinoamericanas. Caracas: Fondo Editorial Tropycos, 1995.
Referências 